\title{
PARA ONDE FORAM OS SINDICATOS?
}

\section{INTRODUÇÃO}

\author{
Marco Aurélio Santana*
}

Desde a Revolução Industrial, quando nasce o operariado moderno, os trabalhadores vêm construindo um grande acervo vivo de experiências e formas organizativas das quais os sindicatos podem ser considerados entre as mais importantes. Ao longo de sua trajetória, os sindicatos se desenvolveram de maneira bastante diversa em termos de setores, categorias, países, regiões etc. Seja em termos da defesa dos interesses imediatos dos trabalhadores, seja a partir da participação em processos políticos e sociais, não se pode fazer uma história, desde o século XIX, sem que se leve em conta o papel destacado deste ator, inescapável quando se analisa a ação coletiva das forças sociais do trabalho ao redor do globo.

As intensas transformações trazidas pelo processo de globalização se estabeleceram, nas últimas décadas, em todo o mundo, modificando, de forma contraditória e heterogênea, padrões econômicos, políticos, sociais e culturais, e conformando a sociedade contemporâ-

* Universidade Federal do Rio de Janeiro. Instituto de Filosofia e Ciências Sociais. Programa de Pós-Graduação em Sociologia e Antropologia e Departamento de Sociologia Largo de São Francisco, 1, Sala 418. Cep: 20051070. Centro-Rio de Janeiro, RJ - Brasil. msantana@ifcs.ufrj.br nea. Como uma de suas expressões mais salientes, elas implicaram, também, significativas reconfigurações dos padrões de trabalho e todo o universo - de atores, normas, práticas etc - que o constitui. Os efeitos dessas mudanças sobre as formas e relações de trabalho, bem como sobre as ações dos trabalhadores, se manifestam de maneira diversa em termos internacionais. Todo o conjunto social sentiu, fortemente, a repercussão de tais mudanças no mundo do trabalho.

Com as organizações dos trabalhadores não foi diferente. Os organismos sindicais, incluindo aí tanto seus aspectos de instituição (sindicato) quanto o de movimento (sindical), passaram a ter muita dificuldade em dar conta do novo cenário que ia se estabelecendo lhe reduzindo grandemente os espaços de manobra e colocando em risco as práticas, ações e conquistas desenvolvidas ao longo do século XX. Os novos tempos pareciam trazer um tipo de sociabilidade que se contrapunha a quaisquer possibilidades de participação de corte coletivo e público.

Porém, se, em um primeiro momento, as transformações pareciam ser letais para 
quaisquer formas coletivas de agenciamento por parte dos trabalhadores, hoje, com padrões mais definidos e estabilizados, já se notam sinais de que, após um cenário de forte impacto, ocorreu um ressurgimento, ou revitalização, do movimento organizativo dos trabalhadores.

Este ressurgimento aparece em processos em que se dá a integração de formas e práticas pré-existentes com novos formatos de organização e orientação sindicais, abrangendo, inclusive, temas anteriormente pouco explorados pelos sindicatos. Desta forma, os sindicatos vêm articulando suas atividades mobilizatórias tradicionais, com formas alternativas de orientação e a participação em outros espaços e instâncias que, em muitos casos, distam daqueles considerados trincheiras históricas. Tudo isso, dependendo do contexto, com maior ou menor grau de efetividade.

A mudança no eixo de intervenção e organização dos sindicatos tem relação direta com o cenário de desregulamentação e de flexibilização de todo o sistema social montado a partir do mundo do trabalho (pense-se, aqui, em um espectro amplo que vai desde as leis de proteção direta ao trabalho até o sistema previdenciário), que passa de uma situação de proteção para um contexto de baixa (ou nenhuma) proteção.

Ter nos sindicatos o alvo central de seus in impactos foi uma das vertentes constituintes 亏े dos processos de transformação que pavimenФं taram o caminho, nas últimas décadas, até a 这 sociedade contemporânea. A dieta neoliberal, ó seguida à risca pelos governos que a encamparam, tinha como um de seus ditames o empreendimento necessário de políticas anti-sinis dicais agressivas. Toda a literatura sociológica a reconhece que a "flexibilização da produção" $\stackrel{\infty}{\sim}$ trouxe grandes problemas para os sindicatos. $\dot{\Delta}$ Alguns autores chegaram mesmo a se perguntar se, com a chamada "reestruturação produtiva”, a evolução dos modelos organizacionais I e o questionamento dos modos tradicionais de representação e de delegação, o sindicalismo não estaria condenado ao desaparecimento.

No entanto, o debate produzido pela percepção dessa “crise” revelou divergências quanto ao modo de interpretar os efeitos das mudanças sobre a instituição e o movimento sindical. Para alguns, esse processo apontava para um declínio inexorável do sindicato, enquanto outros consideram que a "crise" não era da instituição de representação dos trabalhadores, mas de um tipo de sindicato atingido duramente pelas transformações na produção.

Todos esses aspectos históricos, organizativos e políticos têm sido levados em conta na avaliação das dificuldades por que passou o sindicalismo nos países industrializados. Porém, nas análises sociológicas, o seu peso variou conforme a ênfase - otimista ou pessimista - no que se refere à capacidade de reação dos sindicatos aos desafios colocados pelo cenário que se estabeleceu em fins do século XX e início do século XXI.

Não restava dúvida de que os sindicatos deveriam atuar, agora, frente a uma realidade bastante distinta daquela a que se acostumaram, pelo menos, desde o pós-segunda guerra. No caso brasileiro, os sindicatos se desenvolveram, historicamente, lidando com períodos políticos e econômicos diferentes, seguindo a lógica da acumulação capitalista em nosso país. Se levarmos em conta apenas as décadas mais recentes, vamos perceber que, acompanhando o processo de transformações sócio-econômicas então vivido pela sociedade brasileira, o mundo do trabalho no país experimentou realidades bastante distintas quando comparamos sua atuação nos anos de 1980, 1990 e 2000.

A década de 1980 pode ser considerada um período em que os trabalhadores ressurgem no cenário público, com forte mobilização e ascenso de seu movimento, em uma década sindical. No que diz respeito aos anos 1990, estes devem ser caracterizados como de reorientação de práticas e estratégias, nos quais o mundo do trabalho foi varrido por profundas transformações que alterarão sobremaneira suas bases até então vigentes, impactando duramente as formas de organização dos traba- 
lhadores, impondo-lhes ações defensivas, em uma década neoliberal.

Já na primeira década deste século, no Brasil, os trabalhadores e seus sindicatos serão confrontados por outro cenário de atuação. O presente dossiê busca, exatamente, discutir as formas de organização, orientação e atuação do movimento sindical nacional nos anos 20002015, sem deixar de manter uma mirada internacional. Este período nos parece interessante de ser analisado, no caso brasileiro, na medida em que é marcada pelo retorno dos debates e políticas visando ao desenvolvimento econômico e social, pela diminuição do desemprego e retomada do emprego formal, por novas formas de relação entre Estado e sindicatos, de reorganização sindical, de reconfiguração das classes sociais, bem como de ascenso dos movimentos sociais, que têm nas manifestações de junho de 2013 seu ícone maior.

Este mesmo período testemunha, mais recentemente, o que seria o esgotamento de políticas empreendidas no início da década de 2000, indicando a abertura de um outro cenário, no qual pautas mais regressivas quanto ao mundo do trabalho vão sendo recolocadas na mesa, são revisadas políticas de proteção ao trabalho, não se tem um quadro de emprego como antes, o desemprego vai assumindo patamares elevados etc. Junte-se a isso uma forte componente de crise política e econômica. Desta forma, estes são anos em que os sindicatos e o movimento sindical vão experimentar conjunturas diferentes, tendo de responder às mesmas com todas as possibilidades ao seu dispor.

Assim, diante de um cenário bastante alterado de ações, identidades e expectativas, seria interessante indagar para onde foram os sindicatos? Além disso, que formas de organização têm desenvolvido? Que orientações têm seguido? Que formas de luta e mobilização têm empreendido? Que agendas e pautas têm apresentado? Que articulações têm mantido com os movimentos sociais? Como têm mantido sua importância frente aos seus representados que tanto se reconfiguraram?
A pergunta principal, e as que a complementam, não surgem retoricamente já tendo um caráter de afirmação e certeza prévia. A ideia é mesmo perscrutar como um dos atores que servem, há mais de século, entre outras coisas, de canal de organização e condução de conflitividade na sociedade brasileira, está lidando com um país bastante mudado, que dista muito de períodos anteriores que serviram para determinados processos de formação de classe, bem como de correlatos tipos de sindicatos e formas de ação sindical.

Os artigos aqui agrupados dão boas pistas, avançando nesta direção. Abre o dossiê um artigo de Peter Evans sobre as formas pelas quais as forças sociais do trabalho tem buscado, em diversas experiências e sob políticas neoliberais, articular sua dimensão nacional de organização com formas transnacionais em uma renovada arquitetura. Há interessantes indicações de como o sindicalismo brasileiro vai buscando redes globais.

O texto de Iram Rodrigues, a partir de alguns indicadores de sindicalização, chama a atenção para as transformações ocorridas nas décadas recentes no que diz respeito à organização e às condições de trabalho no Brasil, bem como para as formas como elas repercutiram na ação sindical e no "deslocamento" da sindicalização (urbano/rural, masculino/feminino e sul-sudeste/nordeste). Leva-se em conta como todo este processo impacta a Central Única dos Trabalhadores (CUT), maior central de trabalhadores brasileira e projeto sindical mais longevo de nossa história.

Buscando inquirir o que seria uma tal "crise" do sindicalismo brasileiro da última década, a partir de dimensões, entre outras, como número de sindicatos existentes, taxa de filiação sindical, volume de greves e negociação coletiva, o artigo de Adalberto Cardoso mostra que, por exemplo, apesar da forte queda nas taxas de filiação, o sindicalismo tem se mostrado eficiente na negociação coletiva. A crise, na verdade, estaria associada ao ambiente político mais amplo e aos fortes ataques sofridos pelo 
setor hegemônico do sindicalismo, seu projeto político e os partidos a eles alinhados.

$\mathrm{O}$ artigo de Ricardo Antunes e Jair Oliveira, baseando-se na análise da trajetória recente de duas das principais centrais sindicais brasileiras, a Central Única dos Trabalhadores (CUT) e a Força Sindical (FS), mostram que o movimento sindical brasileiro, mormente a CUT, sofreu grandes transformações e inflexões no período, no qual se alterou, de forma significativa, em termos de práticas e concepções que tenderam do combativo ao negocial.

A partir do artigo de Ruy Braga e Marco Aurélio Santana, se pode pensar o lugar tradicional dos sindicatos como canal de organização e condução de conflitividade na sociedade brasileira, a partir de um eixo que articula a reconfiguração das classes sociais hoje, as manifestações atuais da inquietação social e a resposta sindical a essa nova configuração. Analisam-se as diferentes respostas do movimento sindical, com seus encontros e desencontros, frente ao advento do protagonismo político da juventude trabalhadora em condições precárias de vida e de trabalho, bem como as dinâmicas da ação coletiva que daí decorrem.
Por fim, o artigo de Roberto Veras trata da relação entre o movimento sindical e a segmentação das relações de trabalho no Brasil. Neste sentido, toma-se a terceirização como um processo que atualiza e ressignifica tal característica segmentada, desafiando os sindicatos e lhes servindo de limite e possibilidades. Apresentam-se as implicações e os impactos da terceirização na agenda sindical e no futuro do sindicalismo.

Com este dossiê, o leitor tem em mãos um conjunto importante de artigos, com lastro em resultados quantitativos e qualitativos de pesquisa, que auxiliam no entendimento dos caminhos, e porque não descaminhos, seguidos pelo movimento sindical brasileiro nestes anos entre 2000 e 2015. Avaliamos que entender o movimento sindical é uma angulação particular indispensável para o entendimento do que se passa na sociedade.

Recebido para publicação em 15 de agosto de 2015 Aceito em 25 de agosto de 2015

Marco Aurélio Santana - Doutor em Sociologia. Professor do Departamento de Sociologia e do Programa de Pós-Graduação em Sociologia e Antropologia do IFCS/UFRJ. Pesquisador do Núcleo de Estudos Trabalho e Sociedade (NETS-UFRJ). Tem experiência na área de Sociologia, com ênfase em Sociologia do Trabalho, atuando principalmente nos seguintes temas: Trabalho, trabalhadores, lutas sociais e ditadura militar. Publicações recentes: Bravos companheiros: comunistas e metalúrgicos no Rio de Janeiro (19451964) (Rio de Janeiro, 7Letras, 2012); Partidos e trabalhadores na transição democrática: a luta pela hegemonia na esquerda brasileira. Revista Dados (2012); The dilemmas of the new unionism in Brazil: breaks and continuities. Latin American Perspectives (2014), em co-autoria com Ricardo Antunes. 